\title{
STIMULATING CREATIVITY METHODS AND INNOVATIVE PERFORMANCE IN EUROPEAN COUNTRIES
}

\author{
Gabriela Lucia ŞIPOŞ 1 \\ Alin IONESCU ${ }^{2}$
}

DOI: 10.1515/tjeb-2015-0013

\begin{abstract}
A widely debated topic during the last decades focuses on the companies' opportunities to acquire corporate competitiveness due to research, innovation and development. Thus, in the context of increased competition and current global challenges, fostering creativity and innovation is a way to boost economic growth and welfare of European countries. New and original ideas, skills, competencies and innovations they all could enable to achieve competitive advantages. Creative ideas and innovative solutions are crucial for the European countries in order to overcome the current economic crisis.

This paper aims to study the impact of stimulating creativity methods used by companies on innovative performance of the country. The study is based on identifying correlations between using stimulating creativity methods - such as brainstorming sessions, financial incentives for employees to develop new ideas, job rotation of staff, multidisciplinary or cross-functional work teams, non-financial incentives for employees and training employees on how to develop new ideas or creativity - and, by the other hand, innovative performance of European countries, synthetically expressed by Summary Innovation Index. It also quantifies and scales the intensity of influence using each stimulating creativity method.

The results of this study can be a real help for companies to identify the most appropriate stimulating creativity methods in order to increase the innovative performance. Thereby, the main output of the study consists in the fact that using the most effective methods of stimulating creativity the companies will be able to increase their innovative potential and they could obtain long-term competitive advantages.
\end{abstract}

Keywords: Innovation; Innovative Performance; Creativity Methods; Corporate Competitiveness.

\section{JEL Classification: 031.}

\footnotetext{
${ }^{1}$ Associate Professor, West University of Timisoara, Romania.

${ }^{2}$ Postdoctoral Researcher, West University of Timisoara, Romania.
} 


\section{Introduction}

In the context of current economic crisis, globalization and increasing competition among companies, innovation became one of the fundamental elements of increasing corporate performance. This can be explained by the fact that companies need to keep up with the speed of doing business. At the same time, it has been observed the importance of harnessing the new opportunities offered by the global economic environment, because, most often, the companies' possibilities to gain competitive advantages consists in materialization of skills, competencies and new ideas. Therefore, in the current economic climate, innovation is a great opportunity for companies to enter new markets or to develop new products, services, processes or even business models. In this regard, companies need to show flexibility and ability in innovation, taking advantage of circumstantial opportunities.

Consequently, innovation can represent one of the fundamental elements of business progress, being a considerable topic of interest for academic researchers, governments and companies. In this context, it has been observed that there was an increase in the number of papers that have realized the fact that creativity represents an important way to develop innovative processes, services and products, being able to determine the long-term positive effects for all involved parties and for society as a whole (Stolarick \& Florida, 2006; Hollanders \& van Cruysen, 2009; Bobirca \& Draghici, 2011). In other words, innovation became a necessity for companies in the current context of globalization and international business. Creativity, expressed by ideas, attitudes and behaviours, is an essential factor in increasing productivity, profit maximization and development of the companies. Based on this, both scientists and practitioners have realized the growing importance of innovation and fostering it by stimulating creativity methods. In the literature it is also highlighted the importance of innovation and its ability to generate economic growth (Torun \& Cicekci, 2007; Mohnen \& Hall 2013). Nevertheless, we consider that many aspects of the linkages between different methods of creativity and innovation performance have not been completely clarified and deserve to be studied.

As we have already presented, the innovation process is an intensely discussed topic by researchers and practitioners, especially in an economic crisis period, when there is the problem of identifying the necessary funds for innovation and everyone asks about the desirability of investing into such a purpose (OECD, 2009). The most successful enterprises foster innovation, because this represents an important element of the modern management (Ehigie \& McAndrew 2005). In this regard, other authors highlight that innovation represents one of the most commonly researched topics in field of management, especially regarding the organization creativity behaviors and organizational innovation (Miller \& Osborn, 2008). According to other authors, innovation affects economic growth, because knowledge-based entrepreneurship implies a positive effect on economic performance (Alba, Alvarez-Coque, \& Mas-Verdu, 2011). Thus, innovation was recognized to be a key factor for gaining corporate competitiveness and, further, for sustainable economic growth (Crespi, Arias-Ortiz, Tacsir, Vargas, \& Zuniga, 2014).

\section{DE GRUYTER OPEN}

Timisoara Journal of Economics and Business | ISSN: 2286-0991 | www.tjeb.ro Year 2015 | Volume 8 | Issue 1 | Pages: 163 - 182 
In the literature it is considered that enterprises are sustained by innovation and innovation is based on creativity (Thompson, 2004). The linkage between creativity and innovation has been researched by many papers, being a topic with an increasing importance in last decades. In this context, it is recognized that some processes as creativity and innovation require a planning strategy different from common organizational tasks of the company (Mumford, Bedell-Avers, \& Hunter, 2008).

The main differences between creativity and innovation were analyzed in the literature as well. Therefore, creativity assumes creating new ideas, while innovation represents the successful implementation of those ideas in order to increase the benefits received by individuals, companies or society as a whole (Baucus, Norton, Baucus, \& Human, 2008; Rank, Pace, \& Frese, 2004). Thus, creativity methods mean generating ideas, while innovation involves the implementation of this idea. As a consequence of this fact, creativity represents something new, whereas innovation process can be based on ideas generated by previous experiences or different companies. Referring to the linkage between creativity and innovation, some authors remind the results of some previous studies which found that the linear model creativity has a positive effect on research and development which has also a positive effect on innovation (Hollanders \& van Cruysen, 2009). Frequently, the creativity is considered to be the origin of innovation (Sacramento, Dawson, \& West, 2008). One of the main ways for enhancing innovation is represented by using stimulating creativity methods in companies.

An interesting and debated aspect in terms of creativity consists in the different forms that it can take. Thus, over the last few years, it was registered an increase and diversification of the stimulating creativity methods that companies may use in order to enhance innovation. Many researchers and managers have admitted that stimulating creativity at individual level is not enough to increase innovation performance (Baucus et al., 2008). The same study mentions that creativity is ability common to many people, but not all of them develop or use this capability. Thus, exploiting these capabilities depends on a number of contextual factors, many of which may suppress the creativity initiatives. Among these factors that can inhibit the creative process can be included corporate rules, work rules or norms, bureaucratic processes and rigid managers. After a review of the literature, some of the quoted authors stated that creativity can be encouraged through four main ways, such as creating competition, breaking rules or avoiding standard approaches to problems, taking risks and challenging authority (Baucus et al., 2008).

Some studies revealed that innovation, as a result of creativity, can determine a positive economic performance in companies with an environment encouraging initiative. At the same time, the innovation process depends on companies' strategies, resources, capabilities and requirements (Baregheh, Rowley, \& Sambrook, 2009).

Some researchers identified that there were still several questions about how it was possible to define creativity and innovation considering the complexity of the topic and the impact of

\section{DE GRUYTER OPEN}

Timisoara Journal of Economics and Business | ISSN: 2286-0991 | www.tjeb.ro Year 2015 | Volume 8 | Issue 1 | Pages: 163 - 182 
various contextual factors, such as structural or social influences (Agars, Kaufman, \& Locke, 2008). In this sense, they claim that the simple definition of creativity as a generation of new, appropriate and useful ideas is not truly correct, especially because this creative ideas can be recommended for one organization, but it may be unsettling or uninteresting in another context. In other words, creativity should consider also the environment where the new ideas can be applied. The technological and market unexpected circumstances and other environment aspects can also generate opportunities for a company's innovative processes (Tsai \& Yang, 2014). As well, it is considered that creativity can be transformed in innovation only when the novel ideas are successfully implemented at the company or at a unit level (Agars et al., 2008). The innovative ideas can be generated especially by individuals with creative potential (Andriopoulos \& Lowe, 2000). Therefore, creativity should consider also the environment where the new idea can be applied.

Measuring creativity represents an important element in order to know which kind of policies should be taken to improve innovation and company's performance (Hollanders, 2009). According to some authors (Hollanders \& van Cruysen, 2009) creativity can be measured considering some indicators which reflect the creative climate, creativity sector, creativity in research \& development, design activities and competitiveness in design. Using an innovation index (Summary Innovation Index) provided by Eurostat, the quoted authors tested the creativity impact on innovation and discovered significant results for correlations between different creativity dimensions, on one side, and innovation, by the other side.

\section{Data and Methodology}

The research in this paper is focused on two main research hypotheses. The first research hypothesis $(\mathrm{H} 1)$ is that stimulating creativity methods used in a greater extent by companies have a significant impact on the innovative performance in European countries. The second research hypothesis $(\mathrm{H} 2)$ consists in that countries whose companies are using stimulating creativity methods in a higher proportion have more favorable perspectives to increase their innovative performance than countries where these methods are given less importance.

In order to test the first hypothesis ( $\mathrm{H} 1)$, we identified the correlations between each of stimulating creativity methods and the innovative performance of European countries. The main indicators used in econometric analysis are the Correlation Coefficient, the Significance $\mathrm{F}$ of Fisher test and Regression Coefficients of the single factor linear regression models across countries (see Table 1). The method used to estimate the regression coefficients is Least Square Method (Berenson, Levine, \& Krehbiel, 2012).

\section{DE GRUYTER OPEN}

Timisoara Journal of Economics and Business | ISSN: 2286-0991 | www.tjeb.ro Year 2015 | Volume 8 | Issue 1 | Pages: 163 - 182 
Şipoş, G. L. \& lonescu, A. (2015).

Stimulating Creativity Methods and Innovative Performance in European Countries

Table 1. Single Factor Linear Regression

\begin{tabular}{cccc}
\hline $\begin{array}{c}\text { Methods for } \\
\text { Stimulating Creativity }\end{array}$ & Indicators & $\begin{array}{c}\text { Summary Innovation } \\
\text { Index 2010 }\end{array}$ & $\begin{array}{c}\text { Summary Innovation } \\
\text { Index 2011 }\end{array}$ \\
\hline Brainstorming & Correlation & 0.5570 & 0.5280 \\
Sessions & Significance F & 0.0057 & 0.0095 \\
& Regression Coef. & 0.0047 & 0.0043 \\
\hline Multidisciplinary or & Correlation & 0.3840 & 0.3510 \\
cross-functional work & Significance F & 0.0703 & 0.0995 \\
teams & Regression Coef. & 0.0040 & 0.0035 \\
\hline \multirow{2}{*}{ Job rotation of staff } & Correlation & 0.1990 & 0.1840 \\
& Significance F & 0.3625 & 0.3987 \\
\hline Training employees on & Regression Coef. & 0.0028 & 0.0025 \\
how to develop new & Correlation & -0.0680 & -0.0880 \\
ideas or creativity & Significance F & 0.7559 & 0.6895 \\
\hline \multirow{2}{*}{ Non-financial incentives } & Regression Coef. & -0.0009 & -0.0012 \\
for employees & Correlation & -0.2820 & -0.3210 \\
& Significance F & 0.1911 & 0.1348 \\
\hline Financial incentives for & Regression Coef. & -0.0060 & -0.0066 \\
employees to develop & Correlation & -0.5300 & -0.5350 \\
new ideas & Significance F & 0.0092 & 0.0084 \\
\hline
\end{tabular}

Source: Authors' calculations based on Eurostat, IUS 2010 and IUS 2011 data.

The stimulating creativity methods taken into account in this study are: brainstorming sessions, financial incentives for employees to develop new ideas, job rotation of staff, multidisciplinary or cross-functional work teams, non-financial incentives for employees and training employees on how to develop new ideas or creativity.

The selection of stimulating creativity methods used in the model is mainly based on the fact that the literature recognizes their role and importance in increasing the creativity level. Companies have acknowledged several techniques to increase creativity, such as brainstorming or other divergent thinking methods (Adams, 2006). At the same time, brainstorming is recognized to be the most adopted process for generating creative ideas within companies (Heslin, 2009). The use of multidisciplinary or cross-functional work teams in order to stimulate creativity is based on the benefits of a holistic view of employees so that the company's problem to be solved. In the last decades, many surveys showed that job rotation of staff is 
used by an increasing number of companies within developed countries (Ortega, 2001). Using job rotation of staff can help increase creativity by exploring employees' unknown potential and their hidden talent. In order to foster creativity at individual level, a common and effective used method is represented by financial incentives for employees to develop new ideas. Also, in order to enhance employees' creativity, there must be mentioned the existence of non-financial incentives and their important role in a company, that are close by social recognition (Peterson \& Luthans, 2006). The employees can acquire useful and necessary skills also by training on how to develop new ideas and creativity.

The data used to quantify the effect of using these stimulating creativity methods are provided by European Commission, Eurostat based on The Seventh Community Innovation Survey (CIS, 2010), referring to as the „proportion of innovative enterprises by type of methods for stimulating creativity considered highly successful 2008-2010". These data provide an insight into which method is considered successful by enterprises in different European countries for stimulating creativity. It must be emphasized that, although 31 countries participated in the 2010 Community Innovation Survey, unfortunately, from the database of stimulating creativity methods considered highly successful there are missing data for some countries, some of them with high innovative performance as Germany, Sweden and Denmark. Thus, the sample included only the countries for which data were available: 23 European countries out of which 19 are from European Union (Belgium, Bulgaria, Cyprus, Czech Republic, Estonia, Finland, France, Hungary, Ireland, Italy, Lithuania, Luxembourg, Malta, Netherlands, Poland, Portugal, Romania, Slovakia, Slovenia) and 4 are non-EU countries (Norway, Serbia, Turkey and Croatia). In the period referred to in our study Croatia was not a European Union member state. Meanwhile, since July 2013 Croatia became the 28th EU member state.

The innovative performance of European countries is synthetically expressed by Summary Innovation Index, further referred to as SII, provided by European Commission in Innovation Union Scoreboard 2011. Innovation Union Scoreboard 2011 (IUS 2011) is the second edition of the Innovation Union Scoreboard, following the previous European Innovation Scoreboard (EIS). According to Innovation Union Scoreboard 2011, the SII is a composite indicator building on data for 24 indicators, based on 3 main types of indicators (Enablers, Firm Activities and Outputs) and 8 innovation dimensions - Human Resources; Open, Excellent, Attractive Research Systems; Finance and Support; Firm Investments; Linkages \& Entrepreneurship; Intellectual Assets; Innovators; Economic Effects (European Commission, 2011).

Based on innovation performance expressed by SII, countries are classified in Innovation Union Scoreboard 2011 into four categories (European Commission, 2011). The first category is innovation leaders - these are countries whose innovation performance is well above that of the EU27 average (in the period referred to in our study The European Union had 27 member states). The second category is innovation followers and it is grouping countries whose innovation performance is close to that of the EU27. Moderate innovators are countries whose

\section{DE GRUYTER OPEN}

Timisoara Journal of Economics and Business | ISSN: 2286-0991 | www.tjeb.ro Year 2015 | Volume 8 | Issue 1 | Pages: 163 - 182 
Şipoş, G. L. \& lonescu, A. (2015).

innovation performance is below that of the EU27. In the last category (modest innovators) are countries whose innovation performance is well below that of the EU27.

In our research SII values for 2010 and 2011 were used. Due to a lag in data availability, the SII 2010 reflects performance in 2008/2009 and SII 2011 reflects performance in 2009/2010. Because the results of using SII 2010 and SII 2011 in regression analysis are very similar (see Table 1), further research is conducted only based on correlation charts between each stimulating creativity method and SII 2011.

For the second hypothesis $(\mathrm{H} 2)$, the research methodology is based on grouping the European surveyed countries according to their position in SII 2011 scale and a proposed Index of using stimulating creativity methods. Building the proposed Index is based on normalization of values for each country and for each method of stimulating creativity, using the relation:

$$
z_{i}=\frac{x_{i}-\bar{x}}{\sigma}
$$

where:

$\mathrm{z}_{\mathrm{i}}$ is the normalized (standardized) value;

$x_{i}$ is the proportion of using the stimulating creativity methods for each country;

$\bar{x}$ is the average proportion of using each stimulating creativity method across countries;

$\sigma$ is the standard deviation of proportions of using each stimulating creativity method across countries.

Then an average value for normalized values $z_{i}$ of each country for all stimulating creativity methods is calculated. Thus, it results an Index of using stimulating creativity methods for each country (Table 2), which synthetically expresses the proportion of companies in each country that are using all those six stimulating creativity methods. Also, the normalized values for SII 2011 were calculated (Table 2) and in the final part of the paper will result a correlation chart of normalized values with four quadrants in which every surveyed country is placed (see Figure 7). 
Şipoş, G. L. \& lonescu, A. (2015).

Stimulating Creativity Methods and Innovative Performance in European Countries

Table 2. Index of Using Stimulating Creativity Methods and Normalized values for Summary Innovation Index 2011

\begin{tabular}{cccc}
\hline Country & $\begin{array}{c}\text { Index of } \\
\text { Using stimulating } \\
\text { creativity methods }\end{array}$ & Country & $\begin{array}{c}\text { Normalized value for } \\
\text { Summary Innovation } \\
\text { Index 2011 }\end{array}$ \\
\hline Luxembourg & 1.98096 & Finland & 1.85827 \\
Cyprus & 1.91367 & Belgium & 1.36226 \\
Slovenia & 0.70204 & Netherlands & 1.19154 \\
Turkey & 0.45989 & Luxembourg & 1.18121 \\
Serbia & 0.40548 & Ireland & 1.08763 \\
Slovakia & 0.22366 & France & 0.91874 \\
Romania & 0.17680 & Slovenia & 0.66079 \\
Lithuania & 0.15006 & Cyprus & 0.57601 \\
Ireland & 0.12760 & Estonia & 0.48241 \\
Croatia & 0.07225 & Norway & 0.36059 \\
Czech Republic & -0.00449 & Italy & 0.10241 \\
Poland & -0.07534 & Portugal & 0.07880 \\
Malta & -0.11931 & Czech Republic & 0.06100 \\
Estonia & -0.18428 & Hungary & -0.52761 \\
Hungary & -0.24985 & Malta & -0.60753 \\
France & -0.27357 & Croatia & -0.81808 \\
Belgium & -0.30374 & Slovakia & -0.85426 \\
Finland & -0.40880 & Poland & -0.92182 \\
Portugal & -0.56508 & Serbia & -1.01469 \\
Bulgaria & -0.66561 & Romania & -1.15368 \\
Netherlands & -0.75646 & Lithuania & -1.20742 \\
Norway & -1.13075 & Bulgaria & -1.31814 \\
Italy & -1.47511 & Turkey & -1.49844 \\
\hline
\end{tabular}

Source: Authors' calculations based on IUS 2011 data.

\section{Findings}

The six stimulating creativity methods used in this study can be grouped in two categories. First category consists in methods oriented towards shaping a creative organizational environment favorable to innovation (brainstorming sessions, multidisciplinary or cross-functional work teams, job rotation of staff). The second category refers to methods focused on individual (training employees on how to develop new ideas or creativity, non-financial incentives for employees, financial incentives for employees to develop new ideas).

Following the first research hypothesis ( $\mathrm{H} 1)$ mentioned above, based on quantifying the impact of each of stimulating creativity methods on the innovative performance of surveyed European 
countries, our study revealed that there are some correlations between using each of stimulating creativity methods and the innovative performance of those countries.

Thus, the correlation between the proportion of using brainstorming sessions in companies across countries and SII 2011 is shown in Figure 1. The legend of colours used in all charts is as following: green for innovation leaders, blue for innovation followers, yellow for moderate innovators and orange for modest innovators.

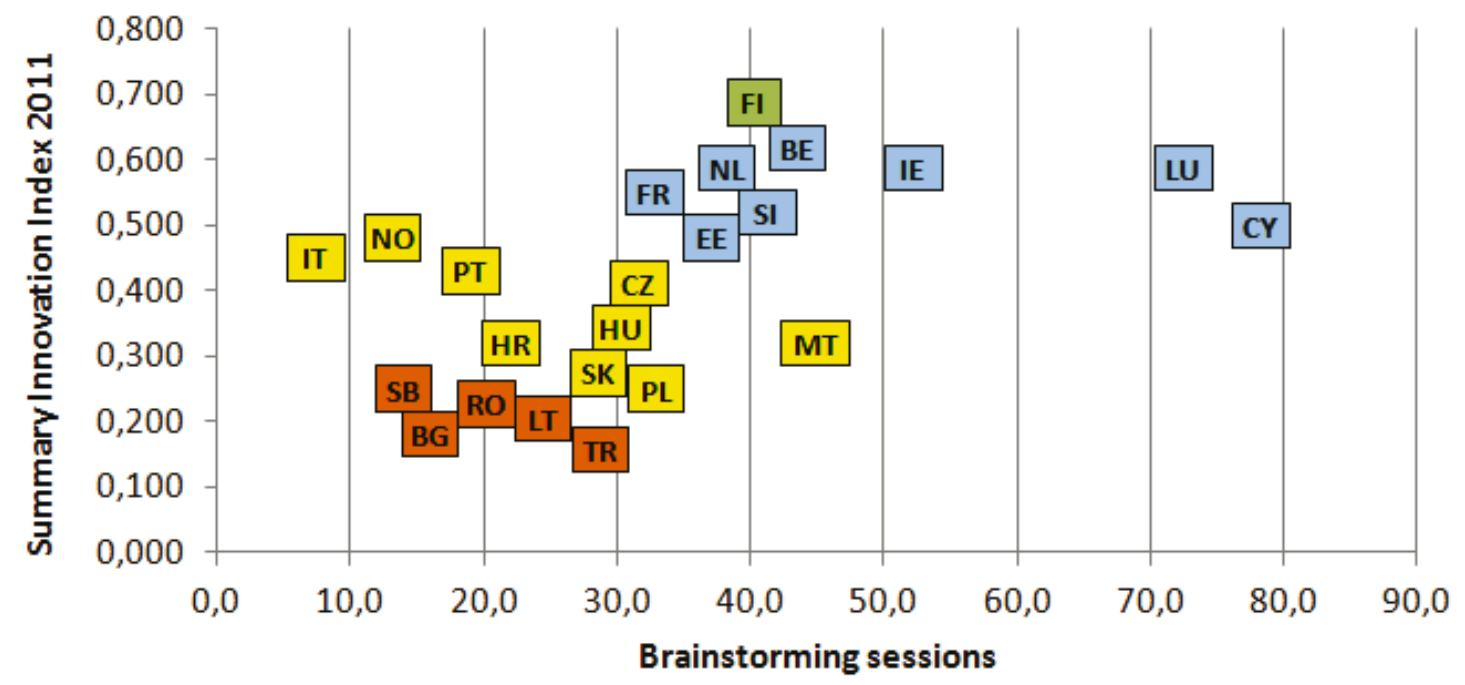

Figure 1. The correlation between using brainstorming sessions and SII 2011

Source: Authors' representation based on European Commission \& Eurostat data.

Among all the methods for stimulating creativity, brainstorming sessions has the strongest impact on obtaining high innovative performance. As shown in Figure 1 most of the companies belonging to countries with high innovative performance (between $30 \%$ and $80 \%$ of companies), which are either innovation leaders or innovation followers, have used brainstorming sessions in order to stimulate creativity. Between these countries, especially Luxembourg and Cyprus stand out, between $70 \%$ and $80 \%$ of the companies belonging to these countries having used brainstorming sessions. On the other hand, this method was used in a much lower extent in countries with more modest innovative performance.

Thus, we can notice a polarization of the analyzed European countries in two areas: highlyperforming innovative countries, whose companies have used in a high proportion brainstorming sessions and, on the other hand, countries with low performance in innovation, whose companies have used in a small proportion brainstorming sessions for stimulating creativity. Moreover, the value of 0.528 for the correlation coefficient and the low level of 0.0095 for Significance $F$ (see Table 1) are emphasizing a strong direct correlation between using brainstorming session as a

\section{DE GRUYTER OPEN}

Timisoara Journal of Economics and Business | ISSN: 2286-0991 | www.tjeb.ro Year 2015 | Volume 8 | Issue 1 | Pages: 163 - 182 
way for stimulating creativity in companies and SII 2011. So, using brainstorming session in a greater extent leads to achieving higher innovative performance.

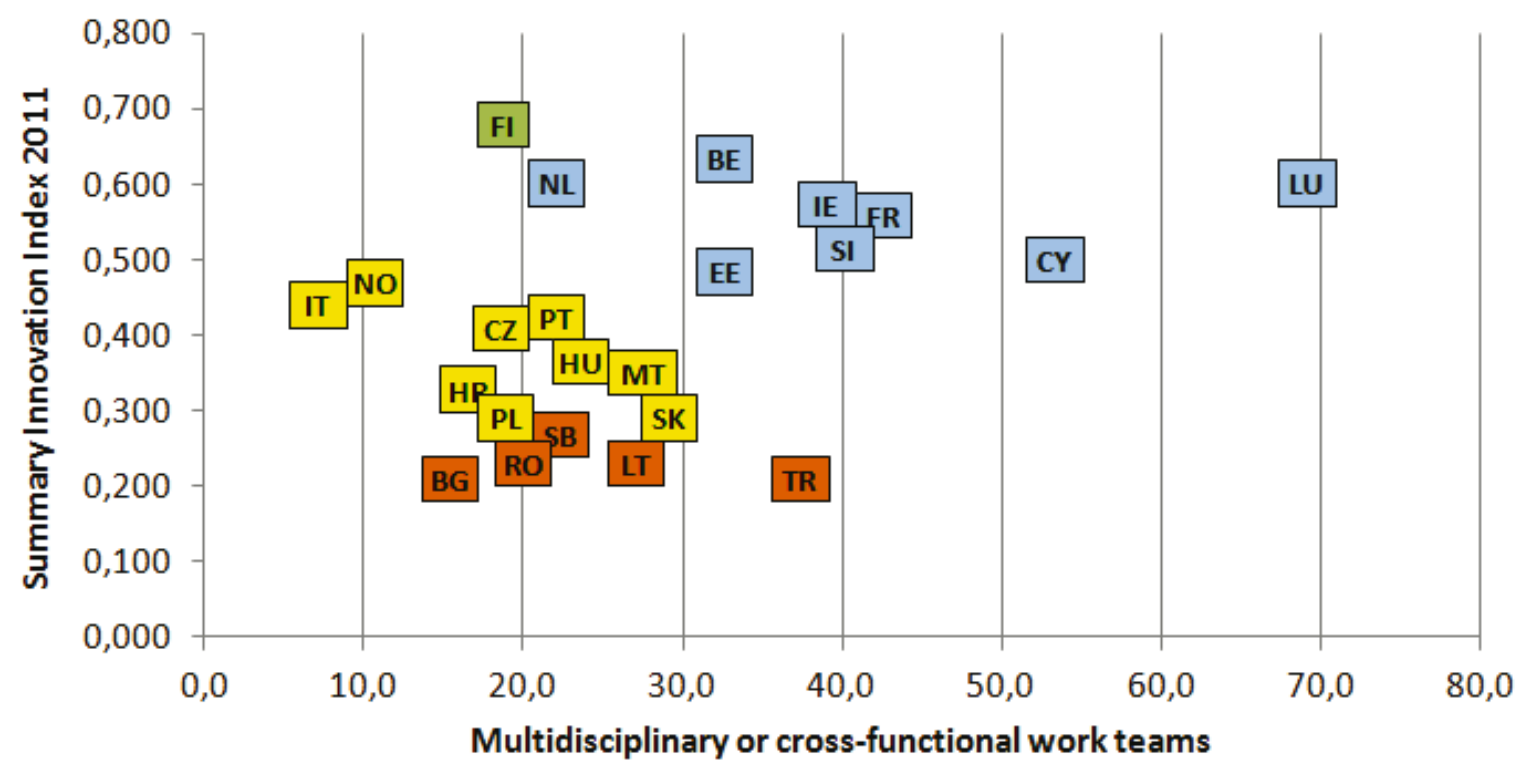

Figure 2. The correlation between using Multidisciplinary or Cross-Functional Work Teams vs. SII 2011

Source: Authors' representation based on European Commission \& Eurostat data.

Multidisciplinary or cross-functional work teams was used as a method of stimulating creativity in a high proportion (over $40 \%$ of companies) in innovation followers countries. Cyprus is again individualized and also especially Luxembourg, as presented in Figure 2. In a small proportion (less than $30 \%$ of companies) multidisciplinary or cross-functional work teams was used in modest innovator countries and moderate innovator countries and only in some countries with high innovative performance, such as Finland and Netherlands.

There is thus a direct correlation between the use of multidisciplinary or cross-functional work teams in companies and the innovative performance. The intensity of the correlation between the use of multidisciplinary or cross-functional work teams in companies and SII 2011 is not as strong compared to the previous presented method, since the correlation coefficient value is only 0.351 and Significance F increased to 0.0995 (see Table 1).

Figure 3 shows the relationship between the proportion of using job rotation of staff in companies across countries and SII 2011. Luxembourg and Cyprus are the countries in which companies have used job rotation of staff in a much higher proportion than other companies belonging to the analyzed European countries. By contrast, less than $30 \%$ of companies from other countries have implemented job rotation of staff. 


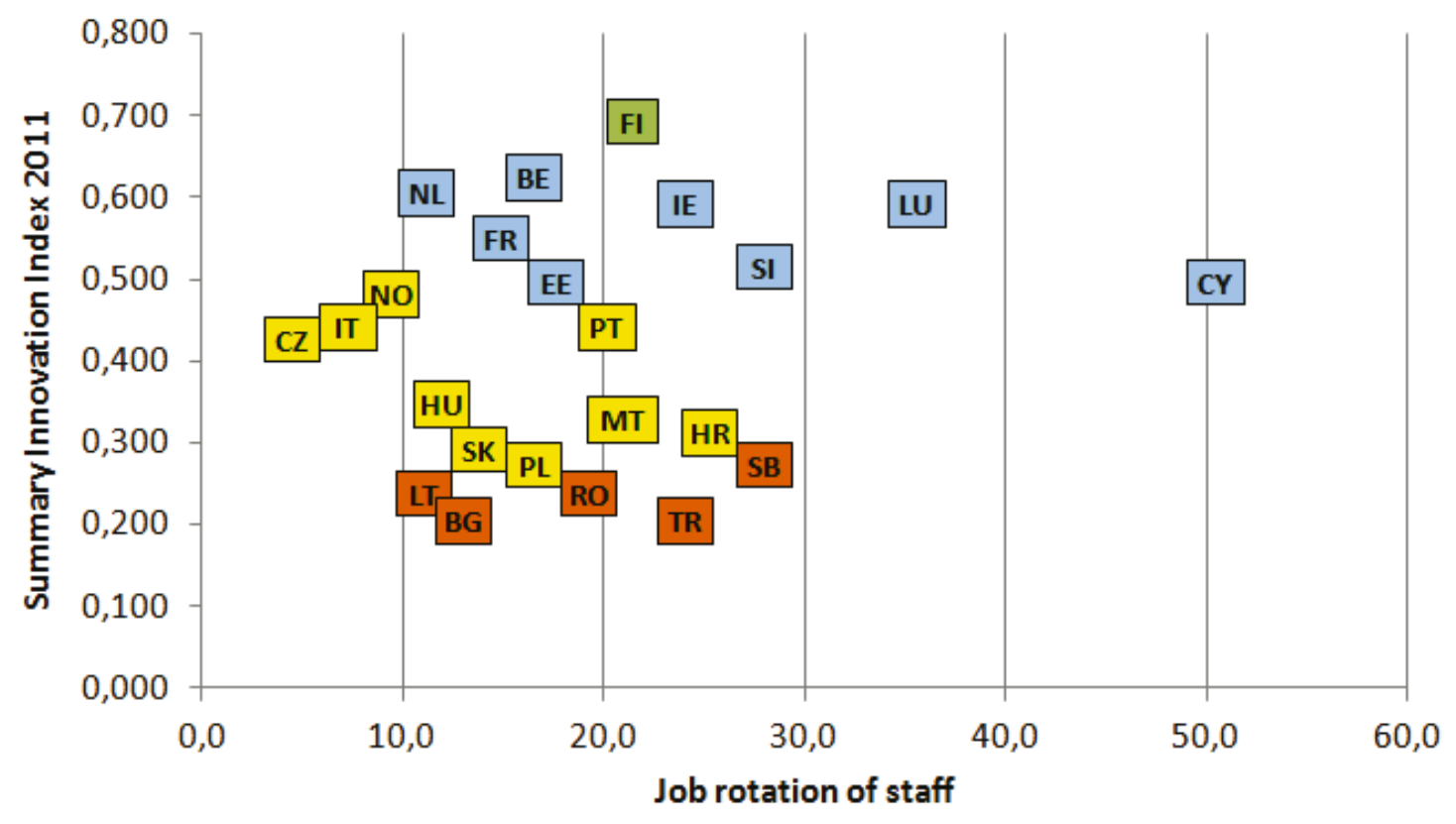

Figure 3. Using Job Rotation of Staff vs. SII 2011

Source: Authors' representation based on European Commission \& Eurostat data.

The smallest proportion of companies that have used job rotation of staff occurred in countries with moderate innovative performance, such as Norway, Italy, Czech Republic, while companies from countries with very low innovative performance have used the job rotation of staff in a proportion close to that of Finland (innovation leader) or innovation followers countries (Netherlands, Belgium, France, Estonia, Ireland, Slovenia). So, using in companies in a greater extent only of job rotation of staff has no influence on innovative performance. It was not identified a statistically significant correlation between using job rotation of staff and the innovative performance of the countries expressed by SII 2011. This aspect is highlighted by the high value of 0.3987 of Significance $F$ and by the low value of 0.184 for the correlation coefficient (see Table 1).

Companies from the all analyzed European countries - innovation leaders, innovation followers, moderate innovators or modest innovators - have used training employees on how to develop new ideas or creativity in proportions ranging between $10 \%$ and 30\% (see Figure 4).

In relation to these, we may distinguish the companies from Cyprus, Luxembourg and Serbia which have used this method in a much higher proportion (51.8\% of companies in Cyprus). On the other hand, only $8.1 \%$ of companies from Italy have used this stimulating creativity method. It may be seen that training employees on how to develop new ideas or creativity does not directly determine innovative performance improvement. The high value of 0.6895 for Significance $F$ and the low negative value of -0.088 for the correlation coefficient 
Şipoş, G. L. \& lonescu, A. (2015).

regarding the relationship between using training employees and SII 2011 (see Table 1) show that it was not identified a statistically significant correlation between training employees on how to develop new ideas or creativity and the innovative performance of the countries.

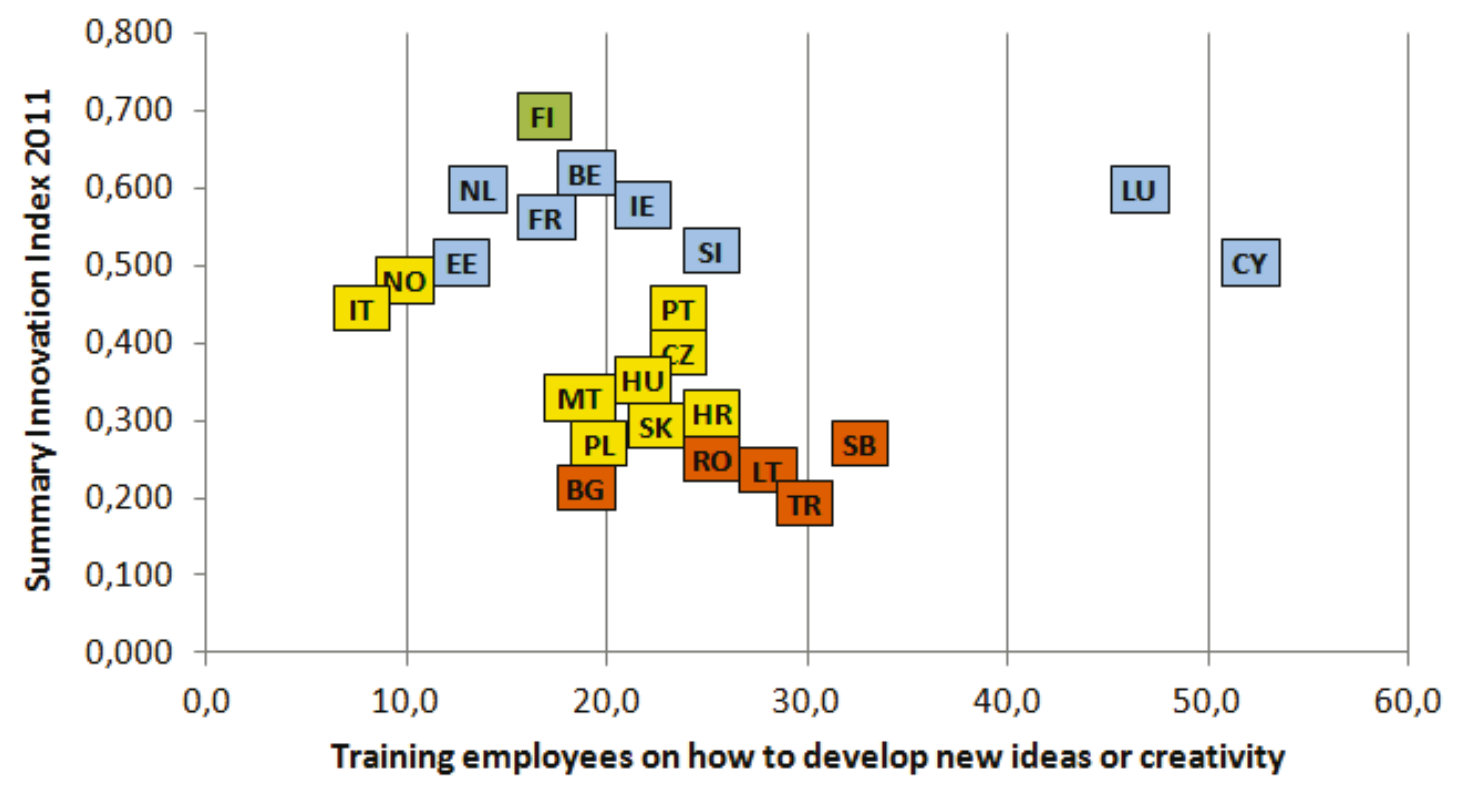

Figure 4. Using Training Employees vs. SII 2011

Source: Authors' representation based on European Commission \& Eurostat data.

Non-financial incentives for employees were implemented in companies from countries with very different innovative performance, from innovation leaders to modest innovators, in similar proportions ranging between $10 \%$ and $25 \%$. There are some exceptions, such as Luxembourg, where $32.4 \%$ of companies used non-financial incentives for employees and Italy, Portugal and Netherlands (third place on the SII 2011 scale, among all surveyed European countries) in which, less than $10 \%$ of companies have used this method. A relatively high proportion of the companies (25\%) from four countries with the most modest innovative performance (Romania, Lithuania, Serbia and Turkey) have used this method to stimulate creativity (see Figure 5).

Although a large proportion of companies from these weak innovative performance countries (well above the proportion of countries with high innovative performance as Finland, Belgium, Netherlands, Ireland or France) have implemented non-financial incentives for employees, this was not reflected in a hearty innovative performance improvement of these countries. This leads to stating that there is a mild negative correlation between the use of non-financial incentives for employees in companies and the innovative performance of surveyed countries. Using only non-financial incentives for 
Şipoş, G. L. \& lonescu, A. (2015).

employees in companies in a great extent has a mild negative influence on obtaining high innovative performance. This mild negative correlation between the use of non-financial incentives for employees in companies and the innovative performance of surveyed countries is evidenced by the correlation coefficient value of -0.321 and by value of 0.1348 for Significance F (see Table 1).

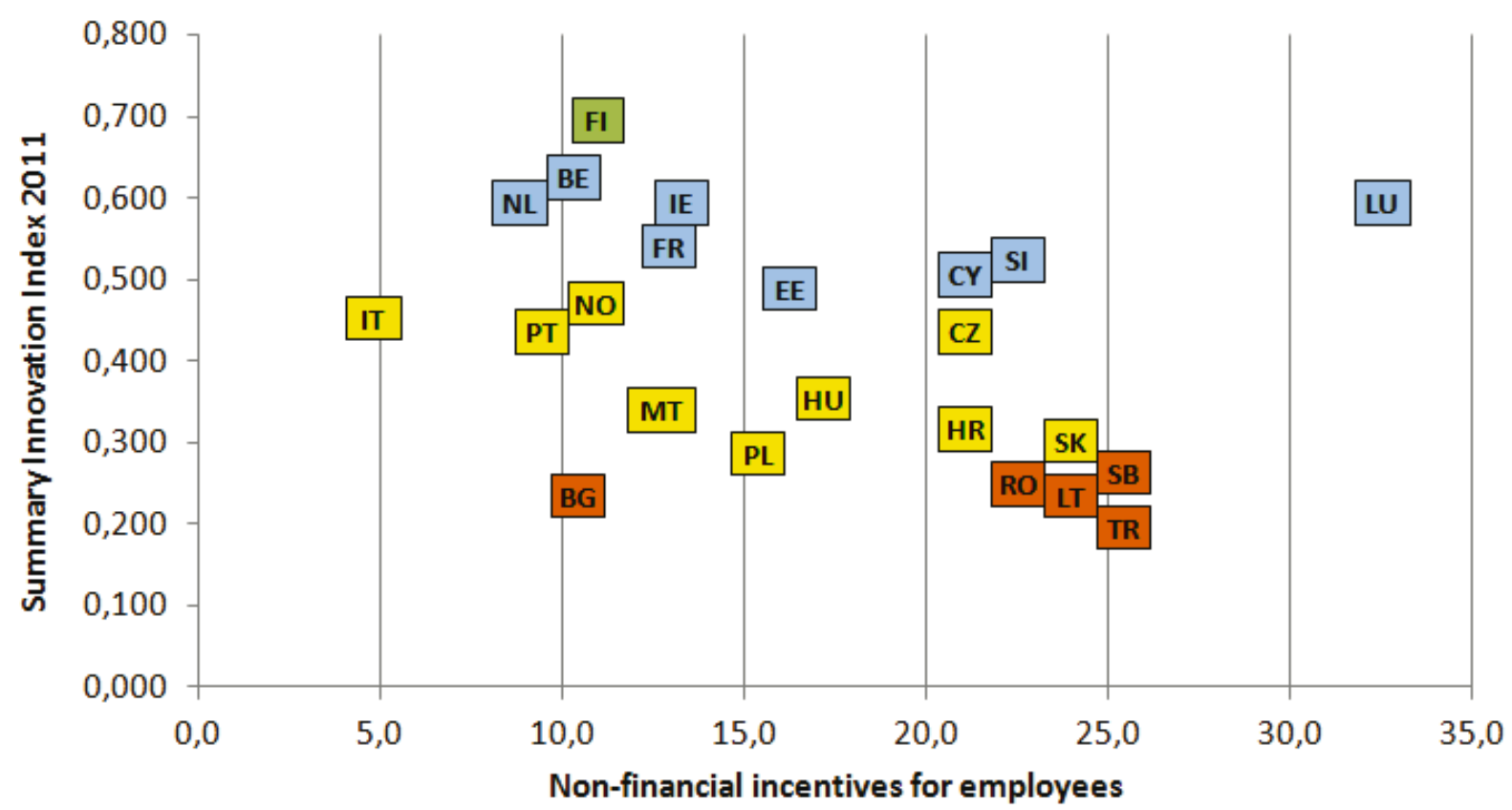

Figure 5. Using Non-Financial Incentives vs. SII 2011

Source: Authors' representation based on European Commission \& Eurostat data.

Using financial incentives for employees to develop new ideas in companies does not determine gaining high innovative performance. Thus, in Figure 6 it can be seen that the highest proportion of companies using this method was found in a modest innovative country (Romania). It is generally seen that modest innovator countries have used this method in a much higher proportion than, for example, the top ranked countries in SII 2011 (Finland, Belgium, Netherlands).

It can be observed that the only implementation of financial incentives for employees to develop new ideas in companies, without being accompanied by a suitable climate for innovation, has a strong negative influence on obtaining high innovative performance. There is a strong negative correlation between these variables, highlighted by the value of -0.535 of correlation coefficient and also by the value of 0.0084 for Significance $F$ regarding the relationship between using financial incentives and SII 2011 (see Table 1). 


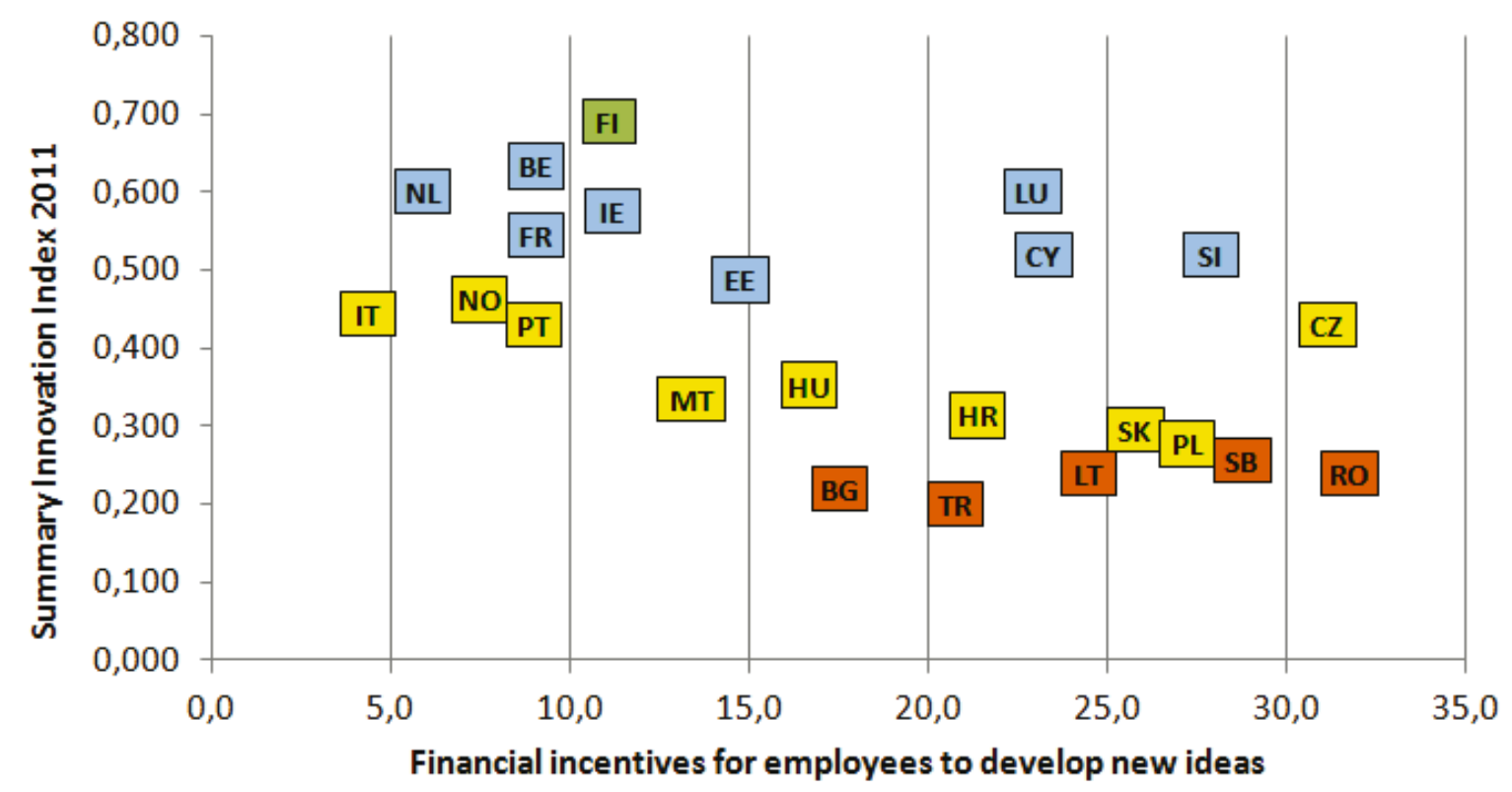

Figure 6. Using Financial Incentives vs. SII 2011

Source: Authors' representation based on European Commission \& Eurostat data.

Among all surveyed countries, it seems that the innovative leader Finland has found the optimal mix of stimulating creativity methods. Companies from this country combined in a harmonious and effective way stimulating creativity methods aimed at shaping an organizational environment favorable towards innovation with stimulating creativity methods focused on employees. It is worth mentioning that companies from Finland have not revealed by using any methods for stimulating creativity in a proportion much higher or much lower than companies in other surveyed countries, but they have used in a balanced way all the six presented methods for stimulating creativity. However, we should underline the fact that in Finland, the share of companies that have used methods aimed at creating an organizational climate favorable towards innovation was much higher than that of companies that have implemented stimulating creativity methods focused on employees.

Based on the econometric analysis results, it can be appreciated that the first research hypothesis (H1) was partially validated. Thus, using stimulating creativity methods in a greater extent in companies has a significant impact on countries' innovative performance only relating to certain methods. The impact intensity is different when using each of the six stimulating creativity methods. Moreover, the influence of using stimulating creativity methods in a greater extent in companies on countries' innovative performance may be positive or, paradoxically, negative. Using in a greater extent of brainstorming sessions or multidisciplinary or cross-functional work teams in companies will have a positive influence 
Şipoş, G. L. \& lonescu, A. (2015).

on the countries' innovative performance. By the other hand, using in a greater extent only non-financial incentives for employees or financial incentives for employees to develop new ideas in companies will have a negative influence on obtaining high innovative performance. There were no proofs regarding the impact of using in a greater extent of job rotation of staff or training employees on how to develop new ideas or creativity on countries' innovative performance.

Following the second research hypothesis (H2), depending on the SII 2011 and the Index of using stimulating creativity methods, countries can be classified into four groups, providing an overview of the innovative performance of the analyzed countries and the evolution prospects of their innovative performance.

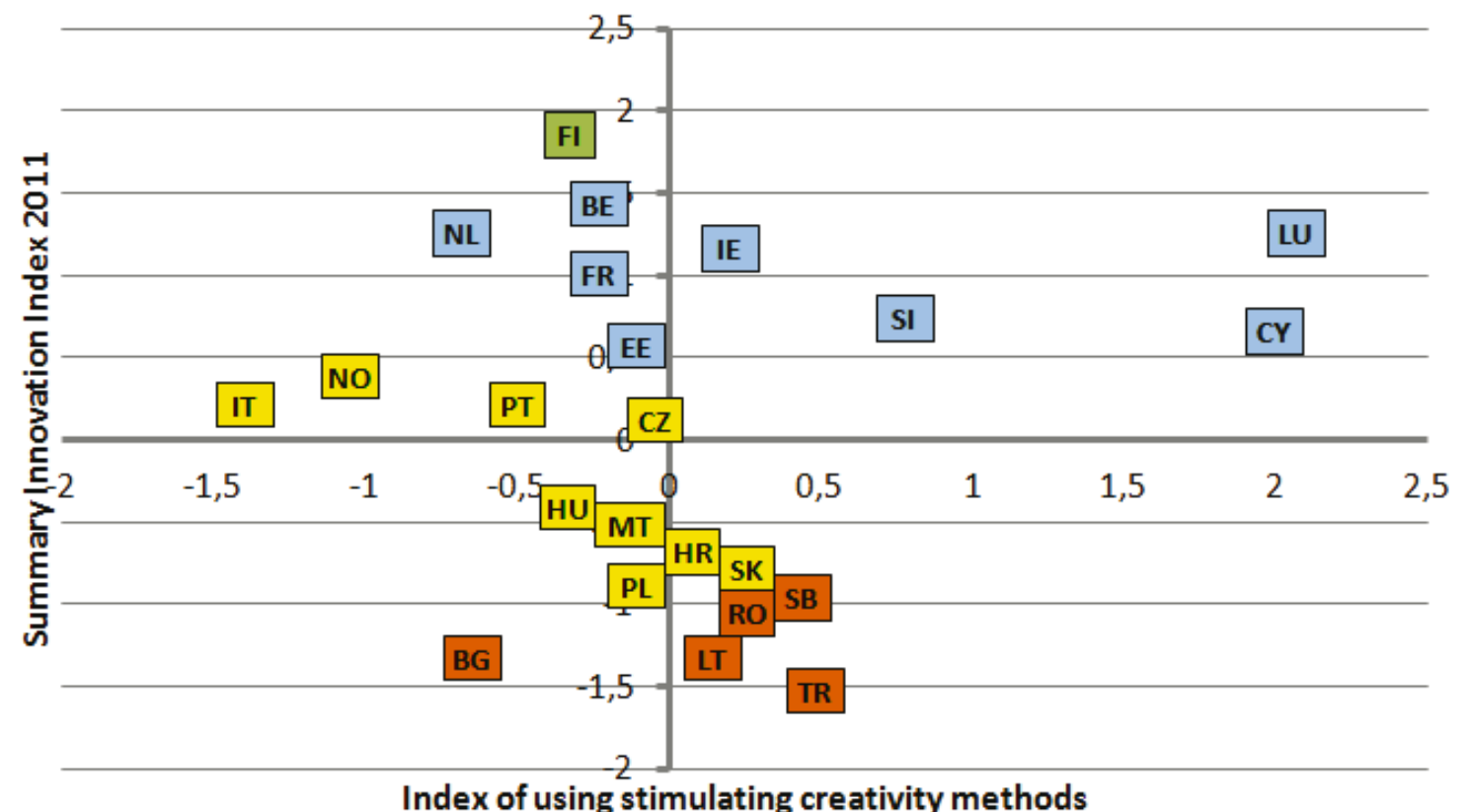

Figure 7. Index of using stimulating creativity methods vs. SII 2011

Source: Authors' representation based on European Commission \& Eurostat data

In the first group are countries with high innovative performance and strong growth prospects of their innovative performance, such as: Luxembourg, Ireland, Slovenia, and Cyprus. The second group brings together countries with high innovative performance and perspective of maintaining their innovative performance at the same level, such as: Finland, Belgium, Netherlands, France, Estonia, Norway, Italy, Portugal, and Czech Republic. The third group put together countries with low innovative performance but positive perspective of their innovative performance like Croatia, Slovakia, Serbia, Romania, Lithuania, Turkey. 
In the fourth group are countries with low innovative performance and poor perspective of their innovative performance like Hungary, Malta, Poland, and Bulgaria.

Countries in the first group have innovative performance above the average of SII 2011 calculated for all analyzed countries and the companies from those countries were widely using above presented stimulating creativity methods. Companies from Luxembourg and Cyprus are highlighted as widely using stimulating creativity methods in order to increase the innovative performance. It is to be emphasized that companies from Luxembourg and Cyprus widely use especially those two stimulating creativity methods that were previously proved in this study to have a positive impact on countries' innovative performance (brainstorming sessions or multidisciplinary or cross-functional work teams). We consider that the countries in this group have excellent perspectives to improve their innovative performance, with real opportunities in the next years to move forward from innovation followers to innovation leaders' category.

In the second group there have been placed countries that have a SIl value for 2011 above the average calculated for all analyzed countries, but the companies from those countries were using in a small extent stimulating creativity methods. Innovation followers like Belgium, Netherlands, France and Estonia have high innovative performance, but due to the fact that the companies from those countries do not place great importance to use of stimulating creativity methods are likely to continue in the next years in the same category of followers. Czech Republic distances itself from the other three moderate innovators countries by the fact that companies are using stimulating creativity methods at a rate that is very close to companies from some countries in the first group.

In the third group there have been placed countries with modest values of SII 2011, situated below the average value calculated for all analyzed countries but the companies from those countries were using stimulating creativity methods in a high proportion (over the average calculated taking into account all the surveyed countries). Among these countries there are both moderate innovators (Croatia, Slovakia) but also modest innovators (Serbia, Romania, Lithuania, Turkey). Given that the companies from these countries were largely using stimulating creativity methods (at a rate comparable to that of the first group of countries such as Ireland), there are favorable conditions for these countries to increase their innovative performance in the coming years and to move forward to innovation followers or to moderate innovators category, as appropriate.

In the last group there have been placed countries with low innovative performance (with values of SII 2011 below the average value calculated for all surveyed countries) while the companies from those countries were using in a small extent stimulating creativity methods. In this group there are placed moderate innovator countries (Hungary, Malta and Poland) and also a modest innovator country (Bulgaria). Countries in this group are not likely to move towards a higher

\section{DE GRUYTER OPEN} Year 2015 | Volume 8 | Issue 1 | Pages: 163 - 182 
innovative performance category. Among all these countries, taking into account simultaneously both the innovative performance and the intensity of using stimulating creativity methods, Bulgaria has the most unfavorable positioning.

Based on these findings, countries whose companies are using stimulating creativity methods in a higher proportion have more favorable perspectives to increase their innovative performance and a more favorable positioning in one of the four groups than countries where these methods are given less importance. This confirms the second research hypothesis (H2). Moreover, noting the innovative performance evolution of the analyzed countries, SII 2012 ranking presented by IUS 2013 further strengthens the validity of the second research hypothesis. Thus, IUS 2013 highlights some important changes compared to the previous edition (IUS 2011). Luxembourg and Ireland (placed in the first group of countries) have improved their innovative performance and the first of them became the most performing among the innovation follower countries. Moreover, Serbia and Lithuania (placed in the third category with positive perspective of their innovative performance) have confirmed the expectations, by shifting from modest innovators towards moderate innovators countries. At the same time, all countries placed in the fourth group (with poor perspective of their innovative performance) have confirmed the expectations: they recorded a decrease of their innovative performance, Bulgaria became the least performing country and Poland achieved a shift from moderate innovators towards the modest innovators category.

\section{Conclusions}

Using stimulating creativity methods does not always have a determining influence, but it certainly is a contributing factor whose effects are seen over time. Definitely, not using stimulating creativity methods guarantees the failure in getting high innovative performance.

Countries whose companies are using stimulating creativity methods in a higher proportion have higher innovative performance and more favorable perspectives to increase their innovative performance than countries where these methods are given less importance. Even countries with low innovative performance have good perspective of improving their innovative performance if their companies are using stimulating creativity methods. In order to get high innovative performances, the companies should combine these methods effectively.

Based on correlations identified in this study, it is shown that the impact of using the stimulating creativity methods is different from one method to another. Thus, regarding those methods oriented towards shaping a creative organizational environment favorable to innovation, using brainstorming session as a way for stimulating creativity in companies has a strong positive impact on increasing the innovative performance of countries. At the same time, using multidisciplinary or cross functional work teams in companies has a positive effect on improving

\section{DE GRUYTER OPEN}

Timisoara Journal of Economics and Business | ISSN: 2286-0991 | www.tjeb.ro Year 2015 | Volume 8 | Issue 1 | Pages: 163 - 182 
the innovative performance of countries, but the impact is not as strong compared to using brainstorming session. But it could not have been identified an impact of using job rotation of staff on improving the innovative performance.

Referring to the methods focused on individual, it could not have been identified an influence of training employees on how to develop new ideas or creativity on increasing the innovative performance. But using only non-financial incentives for employees in companies has a mild negative impact on improving the innovative performance of surveyed countries. Also using only financial incentives for employees to develop new ideas has a strong negative impact on obtaining high innovative performance.

As a result of our detailed analysis, note that using stimulating creativity methods oriented towards creating an organizational environment favorable to innovation in companies had a positive impact on obtaining high innovative performance. Regarding those stimulating creativity methods oriented towards creating an organizational environment favorable to innovation for which we could establish an influence over the innovative performance, the impact was strictly positive, of different intensities.

On the other hand, using mainly stimulating creativity methods focused on individuals has a negative influence on the innovative performance. Regarding those stimulating creativity methods focused on individuals for whom we could establish an influence over the innovative performance, the impact was strictly negative, of different intensities.

So, the only implementation of stimulating creativity methods focused on individuals, did not have the expected impact of increasing the innovative performance. Companies from modest innovator countries have widely used methods for stimulating creativity at individual level, both financial and non-financial incentives, with little effect on improving innovative performance. These countries have poor innovative performance because their companies still have not realized the importance of stimulating creativity methods oriented towards creating an organizational environment favorable towards innovation (especially brainstorming sessions and multidisciplinary or cross-functional work teams), exacerbating the importance of stimulating creativity methods focused on individual (especially non-financial incentives for employees and financial incentives for employees to develop new ideas).

Within innovation leader countries, the share of companies that have used methods aimed at creating an organizational climate favorable towards innovation was much higher than that of companies that have implemented stimulating creativity methods focused on employees. Thus, it follows that in order to obtain high innovative performance the stimulating creativity methods focused on individual must be accompanied and boosted by stimulating creativity methods aimed at shaping an organizational environment favorable towards innovation. Identifying the

\section{DE GRUYTER OPEN}

Timisoara Journal of Economics and Business | ISSN: 2286-0991 | www.tjeb.ro Year 2015 | Volume 8 | Issue 1 | Pages: 163 - 182 
Şipoş, G. L. \& Ionescu, A. (2015).

Stimulating Creativity Methods and Innovative Performance in European Countries

optimal proportion in which these methods should be combined is the key to success in gaining corporate competitiveness and innovative performance for each country.

\section{Acknowledgement:}

This work was cofinanced from the European Social Fund through Sectoral Operational Programme Human Resources Development 2007-2013, project number POSDRU 159/1.5/S/142115 "Performance and excellence in doctoral and postdoctoral research in Romanian economics science domain".

\section{References}

Adams, K. (2006). The Sources of Innovation and Creativity, New Commission on the Skills of the American Workforce. NCEE- National Center on Education and the Economy. Retrieved from http://www.fpspi.org/pdf/innovcreativity.pdf. Accessed 15 October 2014.

Agars, M. D., Kaufman, J. C., \& Locke, T. R. (2008). Social Influence and Creativity in Organizations: A Multi-Level Lens for Theory, Research, and Practice. in M. D. Mumford, S. T. Hunter, \& K. E. Bedell-Avers (Eds.). Multi-Level Issues in Creativity and Innovation, Research in Multi Level Issues (Volume 7, pp. 3-61). Emerald Group Publishing Limited.

Alba, M. F., Alvarez-Coque, J. M. G., \& Mas-Verdu, F. (2011). New Firm Creation and Innovation: Industrial Patterns and Inter-Sectoral Linkages. International Entrepreneurship and Management Journal, 9(4), 501-519. doi:10.1007/s11365-0110210-3

Andriopoulos, C., \& Lowe, A. (2000). Enhancing Organizational Creativity: The Process of Perpetual Challenging. Management Decision, 38, $734-742$.

Baregheh, A., Rowley, J., \& Sambrook, S. (2009). Towards a Multidisciplinary Definition of Innovation. Management Decision, 47, 1323-1339.

Berenson M. L., Levine D. M., \& Krehbiel T. C. (2012). Basic Business Statistics. Concepts and Applications, $12^{\text {th }}$ Edition, New Jersey, USA: Prentice Hall.

Baucus, M. S., Norton, W. I., Baucus, D. A., \& Human, S. E. (2008). Fostering Creativity and Innovation without Encouraging Unethical Behavior. Journal of Business Ethics, 81, 97-115.

Bobirca, A., \& Draghici, A. (2011). Creativity and Economic Development. World Academy of Science, Engineering and Technology, Issue 59. Retrieved from http://waset.org/publications/615/ creativity-and-economic-development. Accessed 18 November 2014.

Crespi, G., Arias-Ortiz, E., Tacsir, E., Vargas, F., Zuniga, P. (2014). Innovation for Economic Performance: The Case of Latin American Firms, Eurasian Business Review, 4(1), 31 50, doi: 10.1007/s40821-014-0001-1.

Ehigie, B. O., \& McAndrew, E. B. (2005). Innovation, Diffusion and Adoption of Total Quality Management (TQM). Management Decision, 43, 925 - 940.

European Commission. (2011). Innovation Union Scoreboard 2011. Retrieved from http://ec.europa.eu/enterprise/policies/innovation/files/ius-2011_en.pdf. Accessed 27 March 2013. 
Şipoş, G. L. \& lonescu, A. (2015).

Stimulating Creativity Methods and Innovative Performance in European Countries

European Commission, Eurostat. Proportion of innovative enterprises by type of methods for stimulating creativity considered highly successful 2008-2010. Retrieved from http://epp.eurostat.ec.europa.eu/statistics_explained/index.php/Innovation_statistic s. Accessed 30 January 2013

European Commission. (2013). Innovation Union Scoreboard 2013. European Commission, Brussels.

Heslin, P. A. (2009). Better than Brainstorming? Potential Contextual Boundary Conditions to Brainwriting for Idea Generation in Organizations. Journal of Occupational and Organizational Psychology, 82, 129-145.

Hollanders, H. (2009). Measuring Innovation: The European Innovation Scoreboard. In E. Villalba, (Ed.), Measuring Creativity, Proceedings for the Conference "Can creativity be measured?", Brussels.

Hollanders, H., \& van Cruysen, A. (2009). Design, Creativity and Innovation: A Scoreboard Approach, INNO Metrics 2008 report, Brussels: European Commission, DG Enterprise.

Miller, C., \& Osborn, R. (2008). Innovation as a Contested Terrain: Planned Creativity and Innovation versus Emergent Creativity and Innovation. In M., D. Mumford, S., T. Hunter, \& K., E. Bedell-Avers (Eds.), Multi-Level Issues in Creativity and Innovation, Research in Multi Level Issues, (Volume 7, pp. 169-189), Emerald Group Publishing Limited.

Mohnen, P. \& Hall, B.H. (2013). Innovation and Productivity: An Update. Eurasian Business Review, 3(1), 47-65, DOI 10.14208/BF03353817.

Mumford, M. D., Bedell-Avers, K. E., \& Hunter, S. T. (2008). Planning for Innovation: A MultiLevel Perspective. in M., D. Mumford, S., T. Hunter, \& K., E. Bedell-Avers (Eds.), MultiLevel Issues in Creativity and Innovation, Research in Multi Level Issues, (Volume 7, pp. 107-154), Emerald Group Publishing Limited.

OECD (2009). Policy Responses to the Economic Crisis: Investing in Innovation for Long-term Growth. OECD, Paris.

Ortega, J. (2001). Job Rotation as a Learning Mechanism. Management Science, 47, 13611370.

Peterson, S. J., \& Luthans, F. (2006). The Impact of Financial and Nonfinancial Incentives on Business-unit Outcomes over Time. Journal of Applied Psychology, 91(1), 156-165.

Rank, J., Pace, V. L., \& Frese, M. (2004). Three Avenues for Future Research on Creativity, Innovation, and Initiative. Applied Psychology, 53(4), 518-528.

Sacramento, C. A., Dawson, J. F., \& West, M., A. (2008). Team creativity: more than the sum of its parts? In M., D. Mumford, S., T. Hunter, \& K., E. Bedell-Avers (Ed.), Multi-Level Issues in Creativity and Innovation, Research in Multi Level Issues, (Volume 7, pp. 269287), Emerald Group Publishing Limited.

Stolarick, K., \& Florida, R. (2006). Creativity, Connections and Innovation: A Study of Linkages in the Montreal Region. Environment and Planning A, 38, 1799-1817.

Thompson, J. (2004). Innovation through People. Management Decision, 42(9), 1082-1094.

Torun, H., \& Cicekci, C. (2007). Innovation: Is the Engine for the Economic Growth? EGE University. The Faculty of Economics and Administrative Sciences Economics IV , 1-54.

Tsai, K-H., \& Yang, S-Y. (2014). The Contingent Value of Firm Innovativeness for Business Performance under Environmental Turbulence. International Entrepreneurship and Management Journal, 10(2), 343-366. doi:10.1007/s11365-012-0225-4 